\title{
Metodología para la Gestión del Capital InTElectual eN Organizaciones de Ciencia y Técnica
}

\author{
Mg. Hernán Yacsabuache Pasapera \\ Director del Instituto de Investigación de la Facultad de Ciencias Financieras y Conitables.
}

\begin{abstract}
RESUMEN
La metodología para la gestión del capital intelectual prepara a las organizaciones para el cambio. Una vez definida sus competencias, dispondrán de un marco estratégico y contarán con un sistema informático que permita reflejar y comparar otros indicadores.

La metodología recibirá una retroalimentación constante del sistema mismo, que medirá en qué capa de desarrollo se encuentra. En función de los programas de ciencia y técnica podrá medirse su efecto económico o social, relación costo beneficio, etc.

La medición de los indicadores permitirá crear y actualizar una base de datos de proyectos, de grupos y centros de investigación y de proyectos de innovación, etc.
\end{abstract}

Palabras clave: Capital intelectual, sistema informático, benchmarking, indicadores, cultura de la medición, autonomía.

\section{INTRODUCCIÓN}

Aborda la necesidad de aplicar técnicas modernas de dirección en los países en vías de desarrollo, la función de las organizaciones dedicadas a la ciencia y la técnica, y la necesidad de gestionar el capital intelectual en este tipo de organizaciones. Para ese fin, se propone usar una metodología en tres etapas: a) Preparación, b) Implantación y c) Crecimiento.

Expone las tareas a realizar en cada una de ellas. Clasifica los indicadores de medición de capital intelectual y explica lo que se recomienda por cada clasificación, a criterio de expertos.

Se propone la siguiente metodología por etapas:

\section{a) Etapa de preparación}

Se preparan las condiciones para implantar el sistema de medición y gestión del capital intelectual.

1. Preparar a la organización para el cambio. Debe lograrse el convencimiento de la utilidad de gestionar el capital intelectual como una clave para el éxito y no como un modo de estar a tono con el discurso académico y empresarial sobre los temas de administración.

2. Tener definidas las competencias (diseños de puesto, mapas de conocimiento, diagnóstico por cada trabajador de las competencias que no tienen y planeación de las vías para alcanzarlas).

3. Disponer de un marco estratégico sólido actualizado y comunicado. Por lo menos 
Misión, Objetivos Estratégicos y Macroindicadores de la organización.

4. Contar con un sistema informático que permita reflejar y comparar otros indicadores operativos además de los contables y financieros.

5. Realizar un benchmarking que permita conocer las mejores prácticas, los indicadores usados en otras organizaciones semejantes del país o del extranjero y los criterios de medida. Se deben considerar los modelos conceptuales que vinculan la ciencia y la tecnología con la sociedad y la integración y las reflexiones e investigaciones que sobre esta vinculación se realizan regional, nacional $e$ internacionalmente

\section{b) Etapa de implantación}

Se definen indicadores y se implanta el sistema de medición.

1. Definir los indicadores a usar en la organización. Deben ser pertinentes, confiables, actualizados, precisos, válidos, verificables, específicos, eficaces y oportunos, y deben agregar valor a la información.

2. El subrayado indica que los indicadores así concebidos deben, pues, alimentar la actividad de los actores que participan en el proceso de generación de conocimiento y de desarrollo tecnológico.

3. Determinar criterios de medida alcanzables por la organización. En la medida que la organización va alcanzando determinado nivel, se deben fijar nuevos criterios de medida y así ir ascendiendo por capas hasta los niveles más altos de gestión.

4. Definir las acciones que contribuyen a mejorar los indicadores y a alcanzar las acciones esperadas.

5. Escoger un área o proceso donde sea posible experimentar con facilidad el sistema diseñado. Debe existir cultura de medición, el efecto de las competencias se pueda verificar fácil y/o rápidamente y que no forme parte de los procesos que se incluyen dentro de la cadena de valor.

6. Incorporar las experiencias obtenidas al sistema.

7. Extender el modelo a toda la organización. Para ello debe lograrse un conocimiento a nivel de toda la organización de los objetivos del sistema, las afectaciones que recibirán los involucrados en su aplicación, qué utilidad tendrá la información que se obtendrá, a quien consultar en caso de dudas. El sistema debe concebirse con suficiente autonomía como para que forme parte de los procesos de la organización, que contemple sus propios mecanismos de ajuste y que se adapte fácilmente a los cambios del entorno.

\section{c) Etapa de crecimiento}

Se recibirá retroalimentación constante del sistema, se medirá en qué capa de desarrollo se encuentra y se decidirá el alza de los criterios de medida para lograr nuevos estadios de desarrollo.

\section{Clasificación de los indicadores de medición de capital intelectual}

La mayoría de los modelos de medición de capital intelectual establecen tres categorías de clasificación:

- Capital humano

- Capital estructural

- Capital relacional (Galán, 2001)

a) El capital humano a los efectos de la ciencia y la técnica comprende los factores de desarrollo (pueden ser personas, grupos, entidades).

b) El capital estructural incluye a los programas científico-técnicos y a los productos de esos programas. 
c) El capital relacional se refiere fundamentalmente a su interacción con la sociedad y a su valoración dentro del Sistema Nacional de Ciencia y Técnica.

Dentro de cada categoría cada indicador puede clasificarse en:

1. Indicadores de insumo.

2. Indicadores de resultado.

3. Indicadores de difusión e innovación tecnológica (indicadores de cooperación y comparabilidad)

Para cada indicador se realizarán análisis comparativos contra períodos base, contra índices externos de los líderes o a nivel mundial. Se recomienda el uso de gráficos, tablas que permitan su mejor presentación y faciliten el análisis.

Los indicadores que se relacionan a continuación constituyen solamente una propuesta, pues cada organización debe adaptarlos a su entorno de desarrollo y en función de cuáles son los fundamentales para medir la gestión científico-técnica. Se obtuvieron a partir de la consulta a trece expertos, seis nacionales y siete extranjeros. Después de realizadas dos rondas de consultas, se escogieron aquellos indicadores con una coincidencia mayor del $20 \%$ (tres o más):

\section{Indicadores de insumo}

Son los más comunes y también los más fáciles de obtener. La metodología para su construcción se basa en el Manual Frascati (OECD, 1993), el cual ha ido adaptándose a los cambios en la estructura productiva, particularmente en lo relacionado con los gastos en Investigación y Desarrollo

\subsection{Gastos en $I+D$}

Es común que la contabilidad tradicional no refleje con exactitud los gastos de I + $\mathrm{D}$ sino que los asocie generalmente a áreas de responsabilidad relacionadas con la investigación. La mejor medición se realizará cuan- do se cuente con una contabilidad basada en las actividades $(A B C)$, que permita registrar cada actividad de $\mathrm{I}+\mathrm{D}$, independientemente de donde ocurra, $y$, a su vez, deseche aquellos gastos operativos de las áreas de I + D que no están en función de la investigación.

\subsection{Gastos en $I+D$ per cápita}

El divisor puede definirse sobre la base del personal de la propia organización o del campo de acción en función del cual se haya diseñado el sistema.

1.3. Personal de $I+D$ (científicos e ingenieros a tiempo completo/ total del personal).

1.4. Incorporación de $\mathrm{I}+\mathrm{D}$ (personas que aportan a $\mathrm{I}+\mathrm{D}$ que no se dedican a tiempo completo / total del personal). Es común que existan muchas personas que aporten en los procesos de investigación y que no están formando parte de las áreas de $\mathrm{I}+\mathrm{D}$, sin embargo su aporte puede ser muy valioso. Para las entidades reguladoras da una idea además de la eficacia del trabajo de socialización de la ciencia.

1.5. Nivel de los investigadores (títulos académicos, títulos de investigación, experiencia).

1.6. Porcentaje de gasto en $I+D$ financiado por la industria, por el gobierno, por organismos de educación superior y por entidades privadas sin ánimo de lucro. Estructura los orígenes de fondos para la actividad científica.

\subsection{Apropiaciones presupuestales por áreas} de conocimiento. Estructura los destinos de fondos de la actividad científica. Se compara con los bancos de necesidades y problemas definidos previamente por la actividad de planificación o con las actividades productivas y de servicios más deficitarios. 


\section{Indicadores de resultado}

Son los que miden el resultado de la asignación de recursos y el producido de las personas e instituciones dedicadas a actividades de $\mathrm{I}+\mathrm{D}$.

Los más conocidos son precisamente los que miden la producción de tipo bibliométrico y de patentes. Estos indicadores no tienen, sin embargo, una base homogénea debido a dificultades de tipo conceptual.

A nivel de país o región se mide por el volumen de exportaciones e importaciones tecnológicas, el pago por patentes, el efecto del proceso de globalización y el nivel de inversión extranjera. Así, sus indicadores «están representados por los ingresos, pagos y saldo de balanza de pagos tecnológica y por la tasa de cobertura».

La balanza de pagos se puede establecer a nivel de organizaciones a partir de lo invertido y lo obtenido en la actividad científica.

En función de los actores del conocimiento pueden usarse indicadores como cantidad de eventos por niveles, cantidad de premios, cantidad y calidad de nuevas relaciones científicas establecidas, relación entre los resultados por cada peso invertido.

En función de los programas de ciencia y técnica podrá medirse su efecto económico o social, relación costo/ beneficio, cantidad de personas involucradas, cantidad de personas beneficiadas, indicadores de género en relación con la incorporación a la actividad científica, indicadores por edades.

Se debe realizar una división de indicadores para sectores de producción en dependencia de la intensidad del uso de las tecnologías, pues las diferencias suelen ser bastante significativas de unos a otros.

La medición de estos indicadores permitirá ir creando y actualizando bases de datos de proyectos, de grupos y centros de investi- gación, de proyectos de innovación, de becarios, de cooperación técnica internacional, ae investigadores en el exterior y de resultaa: de encuestas de desarrollo tecnológico de la industria.

\section{Indicadores de difusión e innovación tecnológica}

Si se tiene en cuenta que éstos se relacionan más con el desarrollo tecnológico, correspondería a una clasificación especial de indicadores de resultados. Su construcción se basa en la estrecha relación que existe entre la tecnología y la industria, y la necesidad de crear un ambiente favorable para la innovación y por consiguiente de cambio técnico.

Estos indicadores permitirían la cooperación de diferentes agentes y el intercambio de información para facilitar la difusión de información a empresas pequeñas y medianas que por su tamaño tendrían limitaciones para inversión en I\&D, pero que a la vez son factor de dinamismo del sector industrial.

La elaboración de estos indicadores responde a la necesidad de favorecer actividades de innovación, así como de realizar un seguimiento y evaluación de las mismas. Los indicadores de innovación y difusión tecnológicas dependen del número de acuerdos de cooperación entre empresas, los objetivos que éstas persiguen con esa colaboración y las características de esas empresas.

\subsection{Visibilidad de la actividad científica}

Se mide por procesos de encuestas que permitan conocer cómo las demás empresas y la sociedad en general, conoce de los resultados científicos obtenidos, se comparan la cantidad de organizaciones que ponen sus resultados en Internet, la cantidad de artículos científicos publicados por los investigadores, las noticias sobre actividades y resultados científicos, el número de impactos efectivos en 
las páginas Web públicas (N. ${ }^{\circ}$ de click / N. ${ }^{\circ}$ de solicitudes).

La gestión para incrementar la visibilidad debe encaminarse a la creación de bancos de proyectos y a lograr su diseminación y generalización.

\subsection{Dinámica del desarrollo de la Ciencia y la Técnica}

Se pueden confeccionar matrices dispersas que permitan establecer los vínculos entre las diferentes organizaciones y las actividades científicas, calcular índices de cohesión entre las actividades fuentes y destinos de las investigaciones o usar cualquier otra técnica que permita determinar la dinámica del crecimiento de la I $+\mathrm{D}$ a nivel de la organización y a nivel social.

\subsection{Grado de inserción en la ciencia mundial}

Parte de analizar la cantidad de becarios y de investigadores participando en proyectos internacionales y de proyectos de cooperación.

\subsection{Grado de difusión y adopción del conocimiento}

Se evalúan las bases de datos de proyectos, las generalizaciones realizadas, las modificaciones realizadas a proyectos por otros investigadores.

\subsection{Impacto de la tecnología}

Teniendo en cuenta que éste es uno de los aspectos con mayor sentido político debe trabajarse profundamente. Medir la cantidad de personas con acceso a la NTIC, clasificadas por edades, género, extracción social; evaluar dentro de lo posible el uso de las tecno- logías con fines de crecimiento o con fines de ocio; el impacto económico de las inversiones tecnológicas (costo / beneficio).

\subsection{Dinámica del cambio tecnológico}

Determinar los períodos de uso de la misma tecnología, los niveles de inversiones por área o sector, las actualizaciones tecnológicas, el tiempo en que se demora el área objeto de estudio en asimilar los adelantos tecnológicos a nivel mundial. Debe tenerse en cuenta las diferencias dinámicas existentes entre las distintas tecnologías.

\subsection{Evolución de la productividad y} la competitividad

Se usarán indicadores propios de cada sector, se calculará la rentabilidad, la productividad, el goodwilly cualquier otro indicador comparativo.

\subsection{Ritmo de innovación}

Se realizarán análisis cronológicos de la actividad de innovación estructurada por sectores o áreas y se obtendrán resultados comparando el ritmo de crecimiento de ese mismo sector o área a nivel mundial.

\section{REFERENCIAS}

- Galán Soteres, Francisco. El modelo KEA, un modelo para la gestión del conocimiento. En Nuevos Patrones de Valor para una nueva economía. Fundación DINTEl, Madrid, 2001, pp. 413-415.

- Jessica Mezza Jaque..[et. al]. Indicadores de capital intelectual en fundaciones tecnológicas. En Nuevos Patrones de Valor para una nueva economía. Fundación DINTEl, Madrid, 2001, pp. 385-395. 